\title{
Risk Factors for Pelvic Lymph Node Metastasis and Recurrence in Patients Undergoing Radical Hysterectomy for Cervical Cancer
}

\section{Xinmei Wang ( $\nabla$ wangxinmei1983@tmu.edu.cn )}

Tianjin Medical University;Tianjin Central Hospital of Obstetrics and Gynecology

https://orcid.org/0000-0002-2874-0946

Hongyuan Zhang

Tianjin Central Hospital of Obstetrics and Gynecology

Juan Xu

Tianjin Central Hospital of Obstetrics and Gynecology

Pengpeng Qu

Tianjin Central Hospital of Obstetrics and Gynecology

\section{Research}

Keywords: Cervical cancer, Pelvic lymph node metastasis, Radical hysterectomy, Lymphovascular space invasion, Pelvic lymphadenectomy, Hemoglobin,

Posted Date: July 19th, 2021

DOI: https://doi.org/10.21203/rs.3.rs-707801/v1

License: (c) (1) This work is licensed under a Creative Commons Attribution 4.0 International License. Read Full License 


\section{Abstract}

Background: Radical hysterectomy and bilateral pelvic lymphadenectomy are standard treatments for early-stage cervical cancer. Pelvic lymph node metastasis (PLNM) is one of the critical factors affecting the postoperative prognosis of patients. Therefore, the identification of preoperative risk factors for PLNM will minimize its occurrence and improve prognosis. The purpose of this study was to investigate the risk factors for PLNM and its recurrence in patients undergoing radical hysterectomy for cervical cancer.

Methods: Medical records of 245 patients who underwent radical hysterectomy and bilateral pelvic lymphadenectomy as primary treatment for the International Federation of Gynaecology and Obstetrics (FIGO) stage IA-IIA cervical cancer between January 2010 and December 2015 at our hospital were reviewed. Age, FIGO stage, preoperative hemoglobin level, depth of stromal invasion, lymphovascular space invasion (LVSI), human papillomavirus(HPV) infection, parametrial infiltration, tumor diameter, number of lymphadenectomies, and pathological type were retrospectively analyzed. All patients were followed up for 5-10 years.

Results: Among the 245 patients, 185 (75.51\%) had no PLNM, whereas 60 (24.49\%) had PLNM. Preoperative hemoglobin level, FIGO stage, LVSI, parametrial infiltration, and tumor diameter differed significantly between the two groups $(P<0.05)$. Multivariate analysis revealed preoperative hemoglobin $<110 \mathrm{~g} / \mathrm{L}$, FIGO stage II, LVSI, parametrial infiltration, and tumor diameter $\geq 4 \mathrm{~cm}$ as significant risk factors for PLNM and recurrence of cervical cancer after surgery $(P<0.05)$. PLNM was identified as the independent risk factor for recurrence in patients with cervical cancer after surgery $(P<0.05)$.

Conclusions: PLNM is an important prognostic indicator for the clinical treatment of cervical cancer. Patients at a high risk of recurrence, especially PLNM patients, should be followed up closely after surgery to ensure the timely detection of recurrence and treatment.

\section{Background}

Cervical cancer is one of the most common malignant tumors leading to death in women worldwide,and approximately 250,000 patients die from this disease each year [1,2]. Radical hysterectomy and bilateral pelvic lymphadenectomy are standard treatments for early-stage cervical cancers. Surgery can not only eliminate the disease, but also provide accurate pathological staging information that clinicians can use to target adjuvant therapy.Pelvic lymph node metastasis (PLNM) is the primary route of metastasis in cervical cancer, directly affecting cervical cancer treatment and prognosis [3-5].

However, only $15 \% \sim 20 \%$ of patients with early cervical cancer have lymph node metastasis [6]. It means that more than $80 \%$ of patients with early-stage cervical cancer may have received unnecessary lymphadenectomy, which can lead to many postoperative complications. Therefore, it is essential to study risk factors affecting PLNM for the clinical treatment of cervical cancer. By preoperatively identifying the risk factors for PLNM, postoperative treatment planning and prognosis evaluation may be optimized. 
The purpose of this retrospective study was to identify the risk factors for PLNM and recurrence, then provide insights into the treatment and prognosis of cervical cancer.

\section{Methods}

\section{Clinical data}

The clinical data of 245 patients with cervical cancer who underwent radical hysterectomy and bilateral pelvic lymphadenectomy at Tianjin Central Hospital of Gynecology and Obstetrics between January 2010 and December 2015 were retrospectively analyzed using the hospital medical records. The inclusion criteria in our study were as follows:1) confirmed diagnosis of cervical cancer by histopathological examination; 2) International Federation of Gynaecology and Obstetrics (FIGO) stage: IA-IIA; and 3) radical hysterectomy and bilateral pelvic lymphadenectomy. The exclusion criteria were as follows:1) incomplete clinical data; 2) preoperative metastatic cervical cancer; 3) cervical lymphoma, cervical melanoma, and other cervical nonepithelial tumors; and 4) case complicated by malignant tumors in other organ systems.

According to the presence or absence of PLNM, the patients were divided into two groups:1) PLNM(-) group: patients without PLNM (185, 75.51\%); and 2) PLNM(+) group: patients with PLNM (60, 24.49\%). All patients were followed up for 5-10 years, and based on follow-up data, they were divided into two groups: 1) Recurrence group: patients with recurrence $(39,15.92 \%)$ and 2$)$ no recurrence group: patients without recurrence $(206,84.08 \%)$.

Age, preoperative hemoglobin level, FIGO stage, depth of stromal invasion, lymphovascular space invasion (LVSI), human papillomavirus (HPV) infection, parametrial infiltration, tumor diameter, number of lymphadenectomies, and pathological type were retrospectively analyzed (Fig. 1).

Patient anonymity was preserved as the data were collected from the hospital's electronic medical records. The research ethics committee of Tianjin Central Hospital of Gynecology and Obstetrics waived the requirement for ethics approval and informed consent because the study used previously stored data.

\section{Statistical analysis}

SPSS version 21.0 (SPSS Inc, Chicago, IL, USA) was used for statistical analysis. The two-by-two or fourfold contingency table (chi-square) test employing exact probabilities was used. Multivariate analysis was performed using a logistic regression model. All tests were two-sided, and the level of significance was set at $P<0.05$.

\section{Results}

The 245 patients included in the study were $27-70$ (45.31 \pm 6.42$)$ years old, of whom $185(75.51 \%)$ had no PLNM, whereas 60 (24.49\%) had PLNM. All patients were followed up for 5-10 years, and 39 (16.25\%) patients relapsed. 


\section{Characteristics associated with PLNM}

Patients in both groups were subdivided into two levels, depending on age, HPV infection, preoperative hemoglobin level, FIGO stage, depth of stromal invasion, LVSI, parametrial infiltration, tumor diameter, number of lymphadenectomies, and pathological type. Age, HPV infection, number of lymphadenectomies, and pathological type did not differ significantly between the the PLNM $(+)$ and PLNM(-) groups; however, preoperative hemoglobin level, FIGO stage, depth of stromal invasion, LVSI, parametrial infiltration, and tumor diameter differed significantly. The number of patients with preoperative hemoglobin $<110 \mathrm{~g} / \mathrm{L}$, FIGO stage II, deep stromal invasion, LVSI, parametrial infiltration, and tumor diameter $\geq 4 \mathrm{~cm}$ in the PLNM(+) group was significantly higher than that in the PLNM(-) group ( $<<$ 0.05) (Table 1). 
Table 1

Characteristics associated with PLNM

\begin{tabular}{|c|c|c|c|c|c|}
\hline Characteristic & $\begin{array}{l}\text { Patients } \\
\text { (n) }\end{array}$ & $\begin{array}{l}\text { PLNM(+) } \\
(n=60 \\
24.49 \%)\end{array}$ & $\begin{array}{l}\text { PLNM(-) } \\
(n=185, \\
75.51 \%)\end{array}$ & $\begin{array}{l}\text { Chi- } \\
\text { square }\end{array}$ & $\begin{array}{l}P \text { - } \\
\text { value }\end{array}$ \\
\hline \multicolumn{6}{|l|}{ Age (years) } \\
\hline$<45$ & 119 & $25(41.67)$ & $94(50.81)$ & 0.775 & 0.424 \\
\hline$\geq 45$ & 126 & $35(58.33)$ & $91(49.19)$ & & \\
\hline \multicolumn{6}{|l|}{ HPV infection } \\
\hline Yes & 165 & $39(65.00)$ & $126(68.11)$ & 0.019 & 0.899 \\
\hline No & 80 & $21(35.00)$ & 59 (31.89) & & \\
\hline \multicolumn{6}{|c|}{$\begin{array}{l}\text { Preoperative hemoglobin level } \\
(\mathrm{g} / \mathrm{L})\end{array}$} \\
\hline$<110$ & 75 & $34(56.67)$ & $41(22.16)$ & 5.998 & 0.015 \\
\hline$\geq 110$ & 170 & $26(43.33)$ & $144(77.84)$ & & \\
\hline \multicolumn{6}{|l|}{ FIGO stage } \\
\hline I & 122 & $13(21.67)$ & $109(58.92)$ & 8.113 & 0.005 \\
\hline II & 123 & $47(78.33)$ & $76(41.08)$ & & \\
\hline \multicolumn{6}{|c|}{ Deep stromal invasion } \\
\hline Yes & 133 & $50(82.76)$ & $83(44.86)$ & 15.394 & 0.000 \\
\hline No & 112 & $10(18.33)$ & $102(55.14)$ & & \\
\hline \multicolumn{6}{|c|}{$\begin{array}{l}\text { Number of } \\
\text { lymphadenectomies }\end{array}$} \\
\hline$<15$ & 138 & $32(53.33)$ & $106(57.30)$ & 0.244 & 0.621 \\
\hline$\geq 15$ & 107 & $28(46.67)$ & $79(42.70)$ & & \\
\hline \multicolumn{6}{|l|}{ LVSI } \\
\hline Yes & 63 & $49(81.67)$ & $14(7.57)$ & 19.304 & 0.000 \\
\hline No & 182 & $11(18.33)$ & $171(92.43)$ & & \\
\hline \multicolumn{6}{|c|}{ Parametrial infiltration } \\
\hline Yes & 53 & $45(75.00)$ & $8(4.32)$ & 22.676 & 0.000 \\
\hline
\end{tabular}




\begin{tabular}{|c|c|c|c|c|c|}
\hline Characteristic & $\begin{array}{l}\text { Patients } \\
\text { (n) }\end{array}$ & $\begin{array}{l}\text { PLNM(+) } \\
(n=60, \\
24.49 \%)\end{array}$ & $\begin{array}{l}\text { PLNM(-) } \\
(n=185, \\
75.51 \%)\end{array}$ & $\begin{array}{l}\text { Chi- } \\
\text { square }\end{array}$ & $\begin{array}{l}P \text { - } \\
\text { value }\end{array}$ \\
\hline No & 192 & $15(25.00)$ & 177 (95.68) & & \\
\hline \multicolumn{6}{|c|}{ Pathological type } \\
\hline SCC & & $52(86.67)$ & $162(87.57)$ & 0.000 & 0.989 \\
\hline Non-SCC & & $8(13.33)$ & $23(12.43)$ & & \\
\hline \multicolumn{6}{|c|}{ Tumor diameter (cm) } \\
\hline$<4$ & 157 & $27(45.00)$ & $130(70.27)$ & 4.647 & 0.034 \\
\hline$\geq 4$ & 88 & $33(55.00)$ & 55 (29.73) & & \\
\hline
\end{tabular}

\section{Logistic regression analysis of risk factors for PLNM}

Logistic regression analysis was used to identify independent predictors for PLMN, and preoperative hemoglobin $<110 \mathrm{~g} / \mathrm{L}$, FIGO stage II, LVSI, deep stromal invasion, parametrial infiltration, and tumor diameter $\geq 4 \mathrm{~cm}$ were found to be independent risk factors for postoperative PLNM of cervical cancer ( $P$ $<0.05)$ (Table 2).

Table 2

Logistic regression analysis of risk factors for PLNM

\begin{tabular}{|c|c|c|c|c|c|}
\hline Characteristic & B & SE & Wald & $P$-value & OR $(95 \% \mathrm{Cl})$ \\
\hline $\begin{array}{l}\text { Preoperative } \\
\text { hemoglobin level }\end{array}$ & 0.741 & 0.313 & 5.390 & 0.015 & $2.115(1.143-3.914)$ \\
\hline FIGO stage & 0.986 & 0.355 & 7.647 & 0.006 & $2.687(1.334-5.414)$ \\
\hline Deep stromal invasion & 1.198 & 0.254 & 15. 129 & $<0.001$ & 3. $612(2.388-5.997)$ \\
\hline LVSI & 1.610 & 0.421 & 15.132 & 0.000 & $4.952(2.212-11.089)$ \\
\hline Parametrial infiltration & 1.161 & 0.427 & 3.879 & 0.001 & $2.614(2.241-4.249)$ \\
\hline Tumor diameter & 0.656 & 0.311 & 4.474 & 0.034 & $1.926(1.049-3.535)$ \\
\hline
\end{tabular}

\section{Characteristics associated with recurrence}

All patients were followed up for 5-10 years, and 39 (16.25\%) patients 
relapsed. The number of patients with preoperative hemoglobin $<110 \mathrm{~g} / \mathrm{L}$, FIGO stage

II, LVSI, deep stromal invasion, parametrial infiltration, tumor diameter $\geq 4 \mathrm{~cm}$, and PLNM in the recurrence group was significantly higher than that in the non-recurrence

group $(P<0.05)$. Age, HPV infection, number of lymphadenectomies, and pathological type did not differ significantly between the two groups (Table 3 ). 
Table 3

Characteristics associated with recurrence

\section{Characteristic}

Patients $(\mathrm{n}=$

No recurrence

$(n=206$,

Recurrence

$84.08 \%)$

$(n=39$,

$15.91 \%)$

$\begin{array}{ll}\text { Chi- } & P \text { - } \\ \text { square } & \text { value }\end{array}$

Age (years)

$\begin{array}{llllll}<45 & 119 & 104(50.49) & 15(38.46) & 1.974 & 0.160 \\ \geq 45 & 126 & 102(49.51) & 24(61.54) & & \\ \text { HPV infection } & & & & & \\ \text { Yes } & 165 & 144(69.90) & 21(53.84) & 2.861 & 0.092 \\ \text { No } & 80 & 62(30.10) & 18(46.15) & & \end{array}$

Preoperative hemoglobin

level $(\mathrm{g} / \mathrm{L})$

$\begin{array}{lccccc}<110 & 75 & 50(24.27) & 25(64.10) & 5.449 & 0.021 \\ \geq 110 & 170 & 156(75.73) & 14(35.90) & & \\ \text { FIGO stage } & & & & & \\ \text { I } & 122 & 111(53.88) & 11(28.21) & 5.217 & 0.029 \\ \text { II } & 123 & 95(46.12) & 28(71.79) & & \\ \text { Deep stromal invasion } & & & & & \\ \text { Yes } & 133 & 101(49.03) & 32(82.05) & 8.185 & 0.004 \\ \text { No } & 112 & 105(50.97) & 7(17.95) & & \end{array}$

Number of

lymphadenectomies

$\begin{array}{llllll}<15 & 138 & 113(54.85) & 25(64.10) & 1.168 & 0.280 \\ \geq 15 & 107 & 93(45.15) & 14(35.90) & & \end{array}$

LVSI

$\begin{array}{lccccc}\text { Yes } & 63 & 33(16.02) & 30(76.92) & 17.29 & 0.000 \\ \text { No } & 182 & 173(83.98) & 9(23.08) & & \\ \text { Parametrial infiltration } & & & & & \\ \text { Yes } & 53 & 25(12.14) & 28(71.29) & 13.974 & 0.002\end{array}$

PLNM, pelvic lymph node metastasis; FIGO, International Federation of Gynaecology and Obstetrics; LVSI, lymphovascular space invasion; HPV, human papillomavirus; SCC, squamous cell carcinoma 


\begin{tabular}{|c|c|c|c|c|c|}
\hline Characteristic & $\begin{array}{l}\text { Patients }(n= \\
245)\end{array}$ & $\begin{array}{l}\text { No recurrence } \\
(n=206, \\
84.08 \%)\end{array}$ & $\begin{array}{l}\text { Recurrence } \\
(n=39 \\
15.91 \%)\end{array}$ & $\begin{array}{l}\text { Chi- } \\
\text { square }\end{array}$ & $\begin{array}{l}P \text { - } \\
\text { value }\end{array}$ \\
\hline No & 192 & $181(87.86)$ & $11(28.21)$ & & \\
\hline \multicolumn{6}{|c|}{ Pathological type } \\
\hline SCC & 214 & $195(37.31)$ & 19 (30.77) & 0.605 & 0.437 \\
\hline Non-SCC & 31 & $11(62.69)$ & $20(69.23)$ & & \\
\hline \multicolumn{6}{|c|}{ Tumor diameter (cm) } \\
\hline$<4$ & 157 & $146(70.87)$ & $11(28.21)$ & 6.217 & 0.034 \\
\hline$\geq 4$ & 88 & $60(29.13)$ & 28 (71.79) & & \\
\hline \multicolumn{6}{|l|}{ PLNM } \\
\hline Yes & 60 & $29(14.08)$ & 31 (79.49) & 18.219 & 0.000 \\
\hline No & 185 & $177(85.93)$ & $8(20.51)$ & & \\
\hline
\end{tabular}

\section{Logistic regression analysis of risk factors for recurrence}

Logistic regression analysis used to identify independent predictors for PLMN revealed preoperative hemoglobin $<110 \mathrm{~g} / \mathrm{L}$, FIGO stage II, LVSI, deep stromal invasion, parametrial infiltration, tumor diameter $\geq 4 \mathrm{~cm}$, and PLMN as independent risk factors for recurrence of cervical cancer $(\mathrm{OR} \geq 1$ and $\mathrm{P}<0.05)$ (Table 4). 
Table 4

Logistic regression analysis of risk factors for recurrence

\begin{tabular}{|llllll|}
\hline Characteristic & B & SE & Wald & $P$-value & O R (95\% Cl) \\
\hline Preoperative hemoglobin level & 0.822 & 0.358 & 5.272 & 0.022 & $2.275(1.128-4.590)$ \\
\hline LVSI & 1.600 & 0.411 & 15.131 & 0.000 & $4.952(2.212-11.089)$ \\
\hline Deep stromal invasion & 0.912 & 0.138 & 8.268 & 0.001 & $1.825(1.675-3.111)$ \\
\hline Parametrial infiltration & 1.032 & 0.423 & 5.714 & 0.011 & $1.620(1.366-2.124)$ \\
\hline Tumor diameter & 0.685 & 0.612 & 5.308 & 0.008 & $1.744(1.187-3.146)$ \\
\hline FIGO stage & 1.195 & 0.439 & 7.412 & 0.006 & $3.303(1.397-7.807)$ \\
\hline PLNM & 1.104 & 0.367 & 9.030 & 0.003 & $3.016(1.468-6.195)$ \\
\hline $\begin{array}{l}\text { PLNM, pelvic lymph node metastasis; FIGO, International Federation of Gynaecology and Obstetrics; } \\
\text { LVSI, lymphovascular space invasion }\end{array}$ & & & & \\
\hline
\end{tabular}

\section{Discussion}

Radical hysterectomy and bilateral pelvic lymphadenectomy are still the primary clinical treatment methods for patients with early-stage cervical cancer. The 5-year survival rate after surgery is reported to be relatively high in patients with FIGO stage IA-IIA [7].. While for some patients, a radical cure is possible, there is a possibility of relapse within 18-24 months after the initial treatment [7]. PLNM is the main metastatic route of cancer cell proliferation and an essential determinant of prognosis $[7,8]$. The incidence of PLNM in cervical cancer patients after surgery is reported to be about $30 \%$ [9]. In this study, the incidence of PLNM was similar at $24 \%$.

The hemoglobin level reduces commonly in the perioperative period [10]. Moreover, anemia occurs in more than one-third of cancer patients, and severe anemia is a risk factor for death in such patients [1113]. The level of hemoglobin, the primary oxygen carrier, directly affects the oxygen supply and oxygen content of the tumor. Preoperative blood transfusion and other strategies do not improve prognosis in cervical cancer patients, and in patients complicated with anemia, the tumor is highly aggressive, further deteriorating the prognosis $[14,15]$. In this study, the number of patients with preoperative hemoglobin < $110 \mathrm{~g} / \mathrm{L}$ was significantly higher in the PLNM $(+)$ group than in PLNM(-) group $(P<0.02)$. And the number of patients with preoperative hemoglobin $<110 \mathrm{~g} / \mathrm{L}$ was significantly higher in the recurrence groups than in the no-recurrence groups $(P<0.03)$. Moreover, preoperative hemoglobin $<110 \mathrm{~g} / \mathrm{L}$ was identified as an independent risk factor for postoperative PLNM and recurrence of cervical cancer after surgery. This finding was consistent with the results of previous studies.

Tumor staging is a defining index of tumor growth and the extent of its spread. As the tumor stage increases, the depth and extent of tumor invasion to the surrounding tissue, the aggressiveness and malignancy of the tumor, and the recurrence rate increase significantly $[3,16]$. LNM rates of la, Ib, Ila, and 
Ilb stages are reported to be $10.5 \%, 13.1 \%, 27.1 \%$, and $50.0 \%$, respectively [17], confirming that LNM increases with advanced FIGO stages. In this study, the number of FIGO stage II cervical cancer patients with PLNM was higher than the number of FIGO stage I cervical cancer patients with PLNM $(P=0.005)$. This finding is consistent with previously reported results.

LVSI, deep stromal invasion, parametrial infiltration, and tumor diameter are closely related to PLNM and the recurrence of early cervical cancer $[18,19]$. LVSI is pathologically confirmed by the presence of malignant tumor cells between two layers of vascular endothelial tissue and is an important prognostic index of cervical cancer. Vascular infiltration is an independent risk factor for PLNM [20, 21]. When cancer cells invade the lymphatic space, they can promote the formation of tumor thrombosis and invade local lymph nodes through the lymphatic vessels, thus inducing parametrial infiltration and PLMN [22, 23]. Consistent with previous studies, in our study, the proportions of patients with LVSI (81.67\%) and parametrial infiltration (75\%) in the PLNM(+) group were significantly higher than those of patients in the PLNM(-) group $(P<0.005)$.

The tumor diameter can reflect the tumor growth time as tumor growth is a continuous invasion and proliferation process. The longer the growth time, the more likely is the lymph node metastasis $[6,7]$. With an increase in tumor diameter and a prolonged growth period, the depth of stromal invasion tends to increase. The contact area between tumor tissue and lymphatic vessels and the risk of LNM also tend to significantly increase $[18,24,25]$. A study on the prognosis of 93 patients with early cervical cancer after surgery found that a tumor diameter $\geq 4 \mathrm{~cm}$ is a risk factor for PLNM and recurrence of cervical cancer [26]. In this study, the number of patients with tumor diameter $\geq 4 \mathrm{~cm}$ and deep stromal invasion differed significantly between the two groups $(P<0.005$ and $P<0.05)$, consistent with previous studies.

Besides preoperative hemoglobin $<110 \mathrm{~g} / \mathrm{L}$, LVSI, deep stromal invasion, parametrial infiltration, and tumor diameter $\geq 4 \mathrm{~cm}$, it was shown that PLNM is an independent risk factor for the recurrence of cervical cancer. LNM occurs in late-stage cancer. Postoperative invasion, metastasis, and recurrence are prone to occur in patients with PLNM. Thus, the postoperative survival rate tends to decrease [27, 28]. Pelvic lymph node dissection can effectively remove metastatic lymph nodes, reduce the tumor load, prevent LNM, and reduce the risk of distant recurrence $[29,30]$. For patients with positive pelvic lymph nodes, the interval between recurrence is significantly shorter than for those with negative lymph nodes, and the risk of recurrence is relatively higher [6]. In this study, the proportion of patients with PLNM in the recurrence group was $(79.47 \%)$ significantly higher than that in the non-recurrence group $(P=0.000)$. PLNM was therefore identified as an independent risk factor for recurrence in patients with cervical cancer after radical hysterectomy and bilateral pelvic lymphadenectomy.

The main strength of this study was the inclusion of patients with PLNM. The prognosis of this group of patients is poor, and adequate preoperative evaluation and postoperative follow-up are needed to improve the prognosis. Moreover, patients with recurrence after surgery were from the same group of patients with PLNM, thereby reducing bias and achieving more accurate results. 
This study also has unavoidable limitations due to its retrospective design. First, we could not assess all variables potentially associated with residual lesions in this single-center study. Furthermore, because the study population was from one hospital, the external validity of our results may be low. Further prospective studies with a larger sample size and a broader context are needed.

\section{Conclusions}

In this study, we found that hemoglobin $<110 \mathrm{~g} / \mathrm{L}$, FIGO stage II, LVSI, deep stromal invasion, parametrial infiltration, and tumor diameter $\geq 4 \mathrm{~cm}$ are independent risk factors for postoperative PLNM and cervical cancer recurrence. Furthermore, PLNM is an independent risk factor for the postoperative recurrence of cervical cancer. LNM is an important prognostic indicator for the clinical treatment of cervical cancer. A comprehensive preoperative evaluation is strongly recommended to improve the curative effect and prognosis of cervical cancer and avoid PLNM. For patients with risk factors for PLNM, careful and systematic pelvic lymphadenectomy should be performed. Patients at a high risk of recurrence, especially those with PLNM, must be strictly followed up, and targeted treatment should be provided after surgery. Further research is needed to determine whether pelvic lymphadenectomy should be attempted only in high-risk individuals.

\section{Abbreviations}

PLNM

pelvic lymph node metastasis

LVSI

lymphovascular space invasion

FIGO

International Federation of Gynaecology and Obstetrics

HPV

human papillomavirus

SCC

squamous cell carcinoma

\section{Declarations}

\section{Ethics approval and consent to participate}

This retrospective analysis was exempt from ethics committee approval at Tianjin Medical University, Tianjin Central Hospital of Gynecology and Obstetrics because the committee did not consider approval was necessary for a retrospective chart review. The data were collected through the institution's electronic medical records while pserving patient anonymity. The research ethics committee waived the requirement for informed consent because the study used pviously stored data. Administrative permissions were not required to access and use the medical records described in our study. 


\section{Consent for publication}

Not applicable.

\section{Availability of data and materials}

Not applicable.

\section{Competing interests}

The authors declare that they have no competing interests.

\section{Funding}

The project name: Establishment and clinical application of early diagnosis system for cervical pcancerous lesions caused by HPV E6 and E7

Contract no.: 19YFZCSY00600

\section{Authors' contributions}

XmW: project development, data collection, manuscript writing.

HyZh: data collection and data analysis.

JY: data collection and data analysis.

PpQ: project development.

All authors have read and approved the final manuscript.

\section{Acknowledgment}

We thank all participants in the study for their invaluable contribution.

\section{References}

1. Ye J, Yin L, Xie P, Wu J, Huang J, Zhou G, et al. Antiproliferative effects and molecular mechanisms of troglitazone in human cervical cancer in vitro. Onco Targets Ther. 2015;8:1211-8. doi:10.2147/OTT.S79899; PMID: 26060406; PMCID: PMC4454221.

2. Peralta-Zaragoza O, Bermúdez-Morales VH, Pérez-Plasencia C, Salazar-León J, Gómez-Cerón C, Madrid-Marina V. Targeted treatments for cervical cancer: a review. Onco Targets Ther. 2012;5:31528. doi:10.2147/OTT.S25123. PMID: 23144564; PMCID: PMC3493318.

3. Gouy S, Morice P, Narducci F, Uzan C, Gilmore J, Kolesnikov-Gauthier H, et al. Nodal-staging surgery for locally advanced cervical cancer in the era of PET. Lancet Oncol. 2012;13(5):e212-20. 
-2045(12)70011-6; PMID: 22554549.. ; ). doi: 10.1016/S1470.

4. Lécuru F, Mathevet P, Querleu D, Leblanc E, Morice P, Daraï E, et al. Bilateral negative sentinel nodes accurately predict absence of lymph node metastasis in early cervical cancer: results of the SENTICOL study. J Clin Oncol. 2011;29(13):1686-91. doi: 10.1200/JC0.2010.32.0432. PMID: 21444878.

5. Macdonald OK, Chen J, Dodson M, Lee CM, Gaffney DK. Prognostic significance of histology and positive lymph node involvement following radical hysterectomy in carcinoma of the cervix. Am $J$ Clin Oncol. 2009;32(4):411-6. doi:10.1097/COC.0b013e31819142dc; PMID: 19451800.

6. Salvo G, Ramirez PT, Levenback CF, Munsell MF, Euscher ED, Soliman PT, Frumovitz M. Sensitivity and negative predictive value for sentinel lymph node biopsy in women with early-stage cervical cancer. Gynecol Oncol. 2017;145(1):96-101. doi: 10.1016/j.ygyno.2017.02.005. PMID: 28188015; PMCID: PMC5873580.

7. Fleming ND, Frumovitz M, Schmeler KM, dos Reis R, Munsell MF, Eifel PJ, et al. Significance of lymph node ratio in defining risk category in node-positive early stage cervical cancer. Gynecol Oncol. 2015;136(1):48-53. doi: 10.1016/j.ygyno.2014.11.010. PMID: 25451695; PMCID: PMC4430191.

8. Polterauer S, Hefler L, Seebacher V, Rahhal J, Tempfer C, Horvat R, et al. The impact of lymph node density on survival of cervical cancer patients. Br J Cancer. 2010;103(5):613-6. doi:10.1038/sj.bjc.6605801. PMID: 20628380; PMCID: PMC2938249.

9. Kwon J, Eom KY, Kim IA, Kim JS, Kim YB, Kim K. Prognostic value of log odds of positive lymph nodes after radical surgery followed by adjuvant treatment in high-risk cervical cancer. Cancer Res Treat. 2016;48(2):632-40. doi:10.4143/crt.2015.085. PMID: 26194370; PMCID: PMC4843724.

10. Zhou H, Xiong Z, Liu JK, Chen SX, Zhou ML, Zhou JH, et al. Low tumor blood flow assessed with perfusion CT correlates with lymphatic involvement in patients with stage T1b non-small cell lung cancer. Thorac Cancer. 2013;4(2):131-7. doi: 10.1111/j.1759-7714.2012.00142.x; PMID: 28920205.

11. Li X, Tan C, Zhang W, Zhou J, Wang Z, Wang S, et al. Correlation between platelet and hemoglobin levels and pathological characteristics and prognosis of early-stage squamous cervical carcinoma. Med Sci Monit. 2015;21:3921-8. doi:10.12659/msm.895016; PMID: 26670918; PMCID: PMC4687949.

12. Lim S, Lee CM, Park JM, Jung SY, Lee KB. An association between preoperative anemia and poor prognostic factors and decreased survival in early stage cervical cancer patients. Obstet Gynecol Sci. 2014;57(6):471-7. doi:10.5468/ogs.2014.57.6.471. PMID: 25469335; PMCID: PMC4245340.

13. Fuso L, Mazzola S, Marocco F, Ferrero A, Dompè D, Carus AP, Zola P. Pretreatment serum hemoglobin level as a predictive factor of response to neoadjuvant chemotherapy in patients with locally advanced squamous cervical carcinoma: a preliminary report. Gynecol Oncol. 2005;99(3);Suppl 1:S187-91. doi: 10.1016/j.ygyno.2005.07.079. PMID: 16185756.

14. Choi YS, Yi CM, Sin JI, Ye GW, Shin IH, Lee TS. Impact of hemoglobin on survival of cervical carcinoma patients treated with concurrent chemoradiotherapy is dependent on lymph node 
metastasis findings by magnetic resonance imaging. Int J Gynecol Cancer. 2006;16(5):1846-54. doi: 10.1111/j.1525-1438.2006.00666.x; PMID: 17009981.

15. Shin NR, Lee YY, Kim SH, Choi CH, Kim TJ, Lee JW, et al. Prognostic value of pretreatment hemoglobin level in patients with early cervical cancer. Obstet Gynecol Sci. 2014;57(1):28-36. doi: 10.5468/ogs.2014.57.1.28. PMID: 24596815; PMCID: PMC3924748.

16. Popa I, Plante M, Renaud MC, Roy M, Têtu B. Negative sentinel lymph node accurately predicts negative status of pelvic lymph nodes in uterine cervix carcinoma. Gynecol Oncol. 2006;103(2):649 53. doi: 10.1016/j.ygyno.2006.04.022. PMID: 16780935.

17. Bourgioti $C$, Chatoupis $K$, Moulopoulos LA. Current imaging strategies for the evaluation of uterine cervical cancer. World J Radiol. 2016;8(4):342-54. doi:10.4329/wjr.v8.i4.342; PMID: 27158421; PMCID: PMC4840192.

18. Dabi Y, Willecocq C, Ballester M, Carcopino X, Bendifallah S, Ouldamer L, et al. Identification of a low risk population for parametrial invasion in patients with early-stage cervical cancer. J Transl Med. 2018;16(1):163. doi:10.1186/s12967-018-1531-6; PMID: 29898732; PMCID: PMC6001133.

19. Lim MC, Lee M, Shim SH, Nam EJ, Lee JY, Kim HJ, et al. Practice guidelines for management of cervical cancer in Korea: a Korean Society of Gynecologic Oncology Consensus Statement. J Gynecol Oncol. 2017;28(3):e22. doi:10.3802/jgo.2017.28.e22. PMID: 28382794; PMCID: PMC5391389.

20. Nanthamongkolkul K, Hanprasertpong J. Predictive factors of pelvic lymph node metastasis in earlystage cervical cancer. Oncol Res Treat. 2018;41(4):194-8. doi: 10.1159/000485840. PMID: 29562222.

21. Park JW, Bae JW. Prognostic significance of positive lymph node number in early cervical cancer. Mol Clin Oncol. 2016;4(6):1052-6. doi: 10.3892/mco.2016.837. PMID: 27284443; PMCID: PMC4887882.

22. Derks M, van der Velden J, de Kroon CD, Nijman HW, van Lonkhuijzen LRCW, van der Zee AGJ, et al. Surgical treatment of early-stage cervical cancer: A multi-institution experience in 2124 cases in the Netherlands over a 30-year period. Int J Gynecol Cancer. 2018;28(4):757 - 63. doi: 10.1097/IGC.0000000000001228; PMID: 29595758.

23. Yu F, Chen Y, Huang L, Nie G. Risk factors of node metastasis in cervical carcinoma. Eur J Gynaecol Oncol. 2016;37(5):662-5. PMID: 29787006.

24. Epstein E, Testa A, Gaurilcikas A, Di Legge A, Ameye L, Atstupenaite V, et al. Early-stage cervical cancer: tumor delineation by magnetic resonance imaging and ultrasound - a European multicenter trial. Gynecol Oncol. 2013;128(3):449 - 53. doi: 10.1016/j.ygyno.2012.09.025. PMID: 23022593.

25. Chen P, Zhang W, Yang D, Zhang W, Gao S. Human papillomavirus status in primary lesions and pelvic lymph nodes and its prognostic value in cervical cancer patients with lymph node metastases. Med Sci Monit. 2019;25:1894-902. doi: 10.12659/MSM.914564; PMID: 30864560; PMCID: PMC6427929.

26. Memarzadeh S, Natarajan S, Dandade DP, Ostrzega N, Saber PA, Busuttil A, et al. Lymphovascular and perineural invasion in the parametria: a prognostic factor for early-stage cervical cancer. Obstet 
Gynecol. 2003;102(3):612-9. doi:10.1016/s0029-7844(03)00569-6; PMID: 12962952.

27. Kwon J, Eom KY, Kim YS, Park W, Chun M, Lee J, et al. The prognostic impact of the number of metastatic lymph nodes and a new prognostic scoring system for recurrence in early-stage cervical cancer with high risk factors: A multicenter cohort study (KROG 15 - 04). Cancer Res Treat. 2018;50(3):964-74. doi:10.4143/crt.2017.346. PMID: 29081219; PMCID: PMC6056979.

28. Matoda M, Takeshima N, Michimae H, Iwata T, Yokota H, Torii Y, et al. Postoperative chemotherapy for node-positive cervical cancer: results of a multicenter phase II trial (JGOG1067). Gynecol Oncol. 2018;149(3):513-9. doi: 10.1016/j.ygyno.2018.04.009. PMID: 29661497.

29. Kenter GG, Hellebrekers BW, Zwinderman KH, van de Vijver M, Peters LA, Trimbos JB. The case for completing the lymphadenectomy when positive lymph nodes are found during radical hysterectomy for cervical carcinoma. Acta Obstet Gynecol Scand. 2000;79(1):72 - 6. doi: 10.1034/j.16000412.2000.079001072.x; PMID: 10646820.

30. Zaal A, Zweemer RP, Zikán M, Dusek L, Querleu D, Lécuru F, et al. Pelvic lymphadenectomy improves survival in patients with cervical cancer with low-volume disease in the sentinel node: a retrospective multicenter cohort study. Int J Gynecol Cancer. 2014;24(2):303-11. doi:

10.1097/IGC.0000000000000043; PMID: 24407577.

\section{Figures}




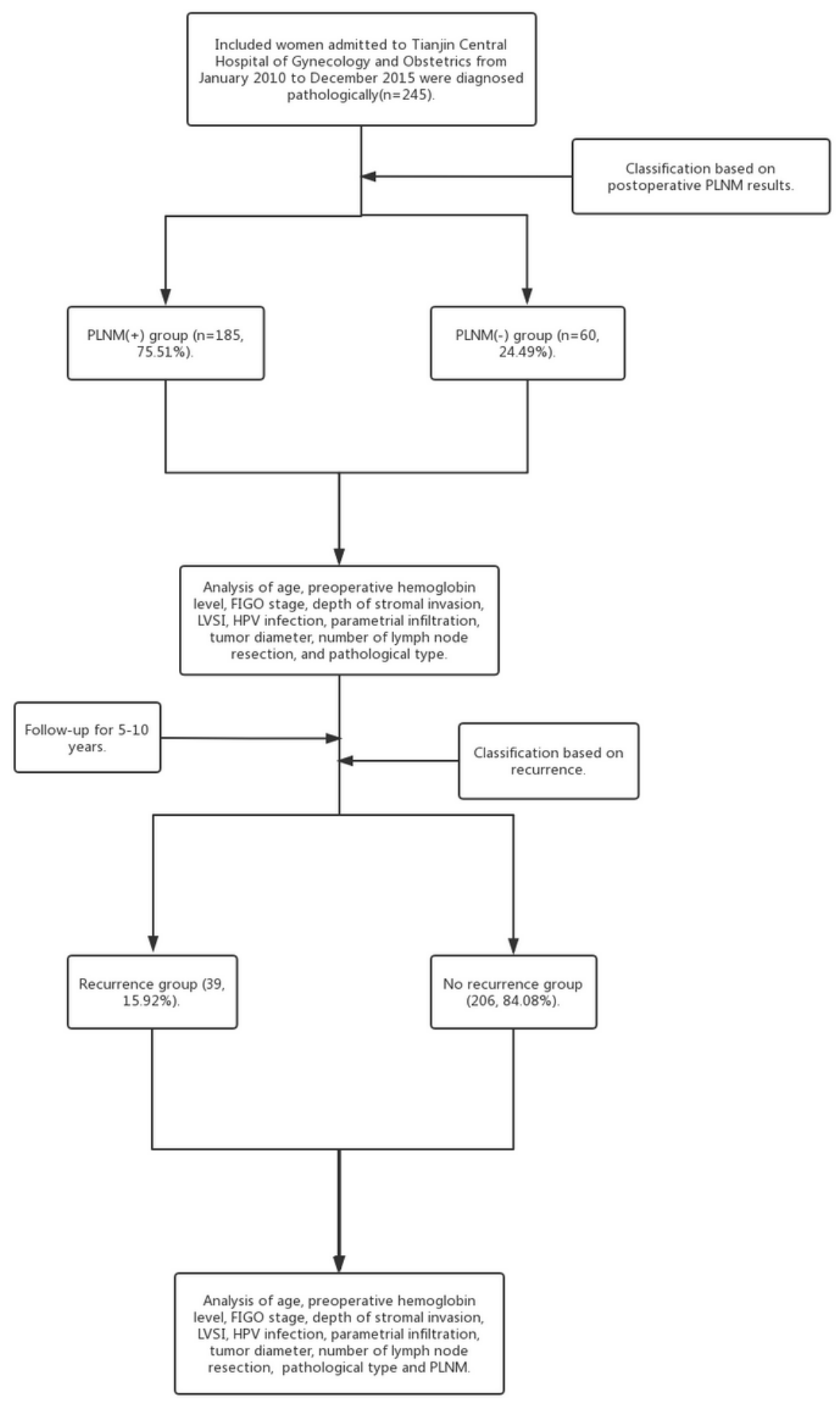

Figure 1

Study flow chart 